\title{
Characteristics of Desertification and Short-Term Effectiveness of Differing Treatments on Shifting Sand Dune Stabilization in an Alpine Rangeland
}

\author{
Xiao Feng ${ }^{1,2}$, Jianjun Qu ${ }^{1,3, *}$, Qingbin Fan ${ }^{1,2}$, Lihai Tan ${ }^{1}$ and Zhishan An ${ }^{1}$ \\ 1 Dunhuang Gobi and Desert Research Station, Northwest Institute of Eco-Environment and Resources, \\ Chinese Academy of Sciences, Lanzhou 730000, China; fengxiao@lzb.ac.cn (X.F.); fanqingbin@lzb.ac.cn (Q.F.); \\ tanlihai09@lzb.ac.cn (L.T.); an1986wen@163.com (Z.A.) \\ 2 University of Chinese Academy of Sciences, Beijing 100049, China \\ 3 Breeding Base for State Key Laboratory of Land Degradation and Ecological Restoration in Northwest China, \\ Ningxia University, Yinchuan 750021, China \\ * Correspondence: qujianj@lzb.ac.cn
}

Received: 9 November 2019; Accepted: 3 December 2019; Published: 6 December 2019

\begin{abstract}
Rangeland desertification is one of the most serious problems threatening the ecological environment and socio-economic development on the eastern Qinghai-Tibet Plateau in China. To combat desertification and reduce its adverse effects, some strategies have been undertaken to stabilize the mobile sand dunes and restore the desertified land. In this study, rangeland desertification with a gradient degree of none, light, medium, severe and extreme was assessed, and short-term effectiveness of different treatments on stabilizing the shifting sand dunes was evaluated by monitoring selected vegetation and soil properties. Results showed that vegetation became thinner and sparser, and soil environment deteriorated significantly under desertification, leading to a poor and low diversity ecosystem. Applying a checkerboard protection strategy in which herb species were planted and using a shrub vegetation planting method without checkerboard protection on mobile dunes for five years, vegetation growth state and soil properties were improved. Soil particles were finer, vegetation restoration was more rapid, and soil nutrient improvement was more apparent at the lower locations of the sand dunes under the checkerboard protection planted with herbs, which performed slightly better in improving soil properties than the shrub planting method alone. A longer time period would be required for vegetation and soils on the sand dunes to be restored to sustain more intensive land use. These findings provide more insight into dune stabilization, allowing effective management in the ecological restoration of desertified rangeland.
\end{abstract}

Keywords: vegetation planting; checkerboard protection; dune topographic locations; particle size distributions; soil nutrients; vegetation coverage

\section{Introduction}

Aeolian desertification, a form of land degradation, is characterized by wind erosion in arid, semiarid and parts of the sub-humid regions in northern China and is mainly induced by excessive human activities [1,2]. Alpine regions on the Qinghai-Tibetan Plateau (QTP) are considered to be a unique geographical unit that is fragile and sensitive to environmental changes, due to the high elevation and cold climate [3]. If not managed properly, rangelands in these fragile alpine regions can easily become desertified. Rangeland desertification in these regions commences with the degradation of grassland or marshland, and continues towards an extremely serious state (e.g., mobile sand dunes), considered the final stage of land degradation $[4,5]$. Climate warming, decreasing precipitation, 
overgrazing, rodent damage, and repeated freezing-thawing actions are thought to be the primary driving factors responsible for the expansion of rangeland desertification on the eastern QTP [6-10].

Desertification adversely affects the survival and growth of rangeland plants and crops, due to strong wind erosion and mobile sand dune movement, threatening pastoral production and inhabitants' living conditions [11]. Comprehensive research has been directed towards the control of aeolian desertification in China during the last 60 years [12]. Mobile sand dunes, generally 10-25 m high, are mainly composed of sand particles which lack cohesion, have high hydraulic conductivity, and are free of vegetation, making wind erosion one of the main limiting factors for plant growth [13]. Engineering measures, such as stone, straw or nylon 'checkerboard' barriers which are a type of vertical barrier with a certain size that serve as wind breaks, can be used to reduce wind-blown activity and facilitate sand stabilization. For example, straw checkerboards with a size of $100 \mathrm{~cm}$ long $\times 100 \mathrm{~cm}$ wide $\times 20 \mathrm{~cm}$ high, have been widely used to slow down the movement of sand particles and stabilize the shifting dunes in northern China, as they can effectively decrease wind speed near the dune surface $[12,14,15]$. Establishment of artificially planted vegetation in desertified areas is another effective method to control desertification and as a consequence improve the regional environment in northern China [16-19]. Enclosure treatments have been used to restore moderately and lightly degraded grasslands by prohibiting grazing, so contributing to the regeneration of vegetation and the reduction of wind erosion [20,21]. However, rangeland degradation in a desert state is difficult to restore naturally, as the rangeland abiotic conditions have been profoundly modified and the capacity of self-recovery within the rangeland ecosystem is limited [4]. As a result, it is difficult for rangeland vegetation to revert to its initial state, even if grazing exclusion is conducted. Therefore, a combination of different artificial input measures is necessary. Many studies have shown that the combinations of two or three treatments selected from the establishment of straw checkerboards, artificially planted vegetation and grazing exclusion have improved topsoil properties and facilitated vegetation restoration, thus are the most promising methods for sand fixation and ecological restoration in semiarid desertified lands $[11,15,22,23]$.

Soil properties and vegetation indexes are important indicators to assess rangeland desertification and effectiveness of restoration strategies in alpine rangelands, as some literature suggests [23-27]. When assessing the short-term effectiveness of restoration, it might be more important to select some soil indicators that could reflect soil dynamics properties, such as soil organic matter, available phosphorus, nitrogen, and other nutrients [5]. Soil particle size distributions, soil bulk density, and soil water retention, which change slowly with time, could reflect long-term variations of soil qualities, thus could be used as indicators to assess rangeland desertification [28].

During the past decade, most desertification research has been concentrated in northern China where there is higher air temperature and lower precipitation than on the QTP. In addition, features of rangeland degradation (but not to a state of desertification), and short-time or long-time effectiveness of grazing exclusion on rehabilitating the degraded rangelands have been widely studied on the eastern QTP. However, features of rangeland desertification and methods for controlling the mobile sand dunes, have been rarely studied on the eastern QTP. Shifting sand dunes lead to sand storms, the loss of land resource, and reductions in land productivity, thus posing negative effects on sustainable regional social-economic development by threatening human health, destroying road and railway networks, and forcing people to vacate traditional lands [29]. It is crucial to understand the features of rangeland desertification to combat and control the shifting dunes, and it is necessary to evaluate whether these methods are effective and viable. Therefore, the main objective in this study is to assess the features of desertification and short-term effectiveness of different treatments to control mobile sand dunes in an alpine rangeland on the eastern QTP, using selected vegetation and soil property indices. 


\section{Materials and Methods}

\subsection{Study Area Description}

This study was carried out during July 2018 in one of the most typical desertified rangelands in Maqu county on the eastern QTP, where the elevation ranges from 3315 to $4779 \mathrm{~m}$, as seen in Figure 1. The sampling sites are located at an elevation of $3500 \mathrm{~m}$. Annual mean air temperature is $1.7{ }^{\circ} \mathrm{C}$, precipitation is $600.4 \mathrm{~mm} /$ year, evaporation is $1274.1 \mathrm{~mm} /$ year, and sunshine duration is $2574.5 \mathrm{~h} /$ year, respectively. The average annual wind speed is $2.3 \mathrm{~m} / \mathrm{s}$, and the maximum wind speed is $20.7 \mathrm{~m} / \mathrm{s}$. Vegetation gross primary productivity is very low because of the cold climate. The vegetation type is dominated by alpine meadow, and sandy soil is widely distributed with a $\mathrm{pH}$ ranging from 7.0 to 7.5 (neutral to slightly alkaline).

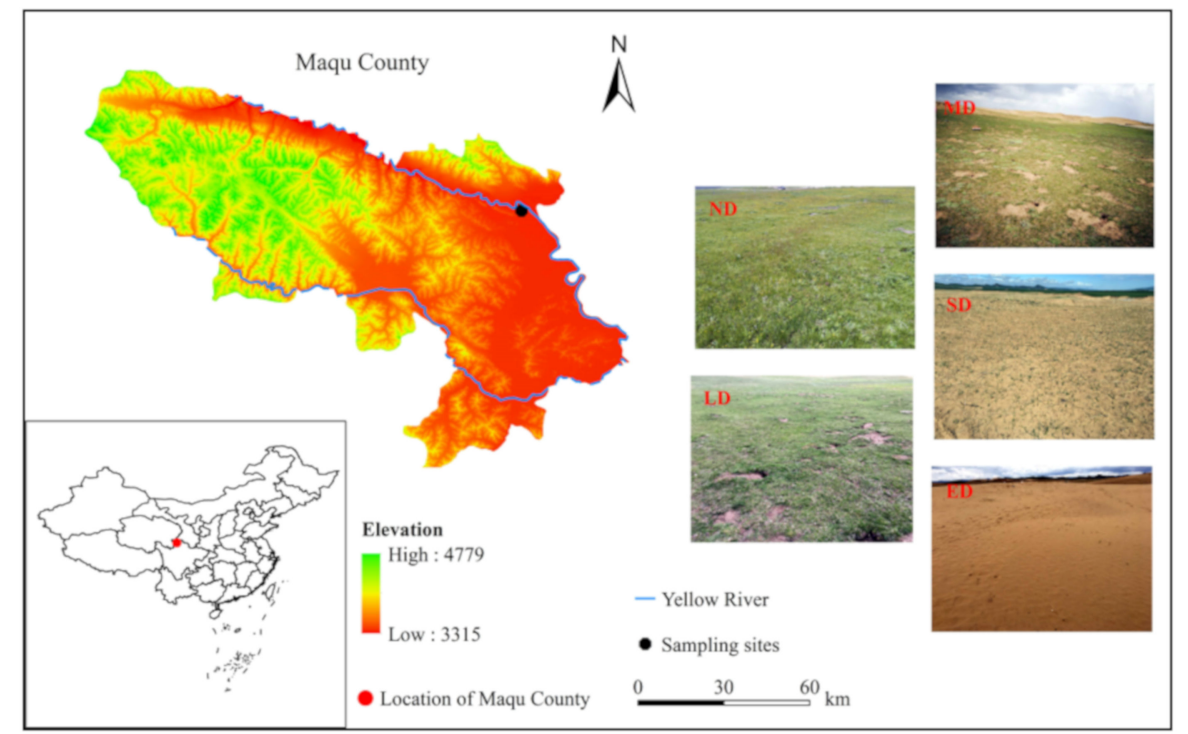

Figure 1. Location of the study area and landscapes of none desertified rangeland (ND), desertified rangelands: lightly (LD), medium (MD), severely (SD), and extremely (ED).

\subsection{Experimental Sampling Design and Analysis}

Soil samples and vegetation data for assessing rangeland desertification were obtained from five desertification gradient sites, which were labelled as none (ND), lightly (LD), medium (MD), severely (SD), and extremely (ED) desertified rangeland, based on observed vegetation coverage. The landscapes of the five sampling sites are presented in Figure 1. The dominant plant species in the ND, LD, MD and SD sites were Kobresia setchwanensis, Kobresia setchwanensis, Carex moorcroftii and Ephedra minuta, respectively.

Treatments for stabilizing the shifting sand dunes in our study included: (a) checkerboard protection planted with Elymus nutans (CE); (b) checkerboard protection planted with Medicago sativa (CM); (c) shrub vegetation planting (Salix oritrepha) without checkerboard protection (S), as shown in Table 1 and Figure 2. The checkerboard framework was made up of nylon sand barriers, $100 \mathrm{~cm} \mathrm{long} \times$ $100 \mathrm{~cm}$ wide $\times 20 \mathrm{~cm}$ high. The plants Elymus nutans and Salix oritrepha are widespread native species, while Medicago sativa is an introduced edible herbaceous species.

After stabilizing the shifting sand dunes for five years, soil samples and vegetation data for evaluating the effectiveness of each method were collected along the windward slope of the bottom (BOT), middle (MID) and top (TOP) of sand dunes treated with CE, CM and S, respectively. Soil samples collected from the adjacent bare sand dunes were used as the control treatment (CK).

At each sampling site, five random quadrat plots were surveyed for vegetation and three sampled for soil. The quadrat plots were $0.5 \mathrm{~m} \times 0.5 \mathrm{~m}$ for herb study in the desertified rangeland sites, $2 \mathrm{~m} \times 2 \mathrm{~m}$ for shrub treatment, and $1 \mathrm{~m} \times 1 \mathrm{~m}$ for herb treatment on the mobile sand dunes. All soil 
samples were collected from $1 \mathrm{~m} \times 1 \mathrm{~m}$ quadrat plots. In each quadrat plot, vegetation coverage, plant height and dried aboveground biomass were recorded for herbs, and plant density, height and canopy were recorded for shrubs.

Table 1. Five years treatments for fixing the mobile sand dunes.

\begin{tabular}{|c|c|c|c|c|}
\hline Abbreviations & Sand Fixing Treatments & $\begin{array}{l}\text { Vegetation } \\
\text { Types }\end{array}$ & $\begin{array}{l}\text { Vegetation } \\
\text { Species }\end{array}$ & $\begin{array}{l}\text { Number of Sand } \\
\text { Fixing Years }\end{array}$ \\
\hline $\mathrm{CE}$ & $\begin{array}{l}\text { Checkerboard protection planted } \\
\text { with herbaceous vegetation }\end{array}$ & Herb & Elymus nutans & 5 \\
\hline $\mathrm{CM}$ & $\begin{array}{l}\text { Checkerboard protection planted } \\
\text { with herbaceous vegetation }\end{array}$ & Herb & Medicago sativa & 5 \\
\hline$S$ & Shrub vegetation planting method & Shrub & Salix oritrepha & 5 \\
\hline
\end{tabular}

CE-the treatment of checkerboard protection planted with Elymus nutans, CM-the treatment of checkerboard protection planted with Medicago sativa, S- the treatment of shrub vegetation planting method.

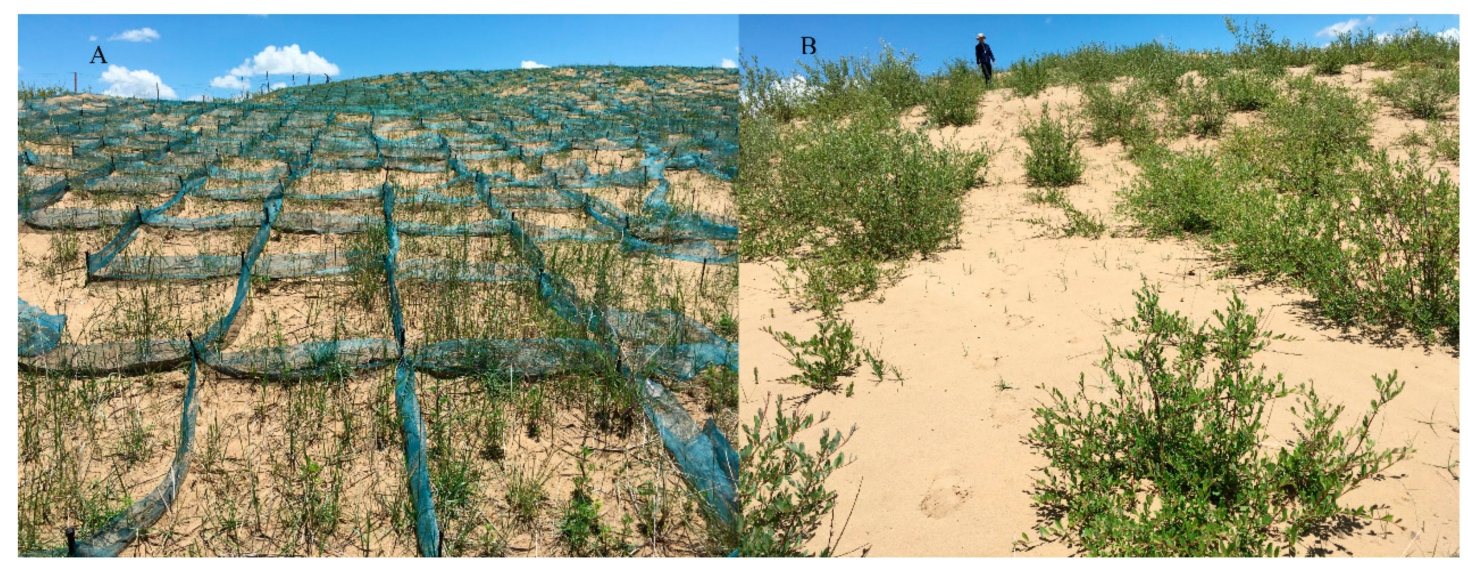

Figure 2. Sand fixing treatments on the shifting dunes. (A) represents the checkerboard protection planted with herbaceous vegetation, and (B) represents the shrub vegetation planting method.

Soil properties could properly reflect variations under desertification within the uppermost $30 \mathrm{~cm}$; however, to reflect variations in soils on sand dunes under short-term stabilization effectively, it could be better for us to collect soil samples on the dune top surface but not to a deeper depth, as soil degradation and restoration are both very slow processes $[17,30,31]$. Therefore, soil samples for analyzing soil particle size distributions (PSDs) were collected from soil layers of 0-5, 5-10, 10-20 and $20-30 \mathrm{~cm}$ in the desertified sites, and from the $0-5 \mathrm{~cm}$ soil layer in the sites under stabilization treatments. Soil samples for analyzing soil organic carbon (SOC), total nitrogen (TN), available nitrogen (AN), available phosphorus (AP), and available potassium (AK) were collected from soil layers of $0-30 \mathrm{~cm}$ in the desertified sites, and from the $0-5 \mathrm{~cm}$ soil layer in the sites under stabilization. Soil samples in a given layer were collected from 8-10 points and mixed homogeneously to obtain a composite sample. Soil samples for analyzing soil water content (SW) and soil bulk density (BD) were collected from soil layers of $0-10,10-20$ and $20-30 \mathrm{~cm}$ in the desertified sites using a stainless-steel cutting ring with a volume of $100 \mathrm{~cm}^{3}$.

The aboveground portions of herbaceous plants were cut flush with the ground. Plant samples were rinsed with water and dried in a constant-temperature oven at $85^{\circ} \mathrm{C}$ until constant weight was attained [23]. Vegetation coverage was assessed by the vertical projection method [15,22]. Plant canopy size was determined by the average value of the east-west and north-south length of the shrub.

Soil samples were air dried and hand sieved through 2 and $0.5 \mathrm{~mm}$ sieves to remove roots and other debris. Soil particle sizes were measured by a laser diffraction particle-size analyzer (mod. 2000, Malvern Instruments, Malvern, UK) with a measurement range of 0.02-2000 $\mu \mathrm{m}$ and a repeated measurement error of less than $2 \%$, thus yielding the volumetric distributions of soil PSDs [32]. Following the classification system from the United States Department of Agriculture $[17,20]$, we 
measured the particle sizes in 5 classes: <2 (clay), 2-50 (silt), 50-100 (very fine sand), 100-250 (fine sand) and 250-500 $\mu \mathrm{m}$ (medium sand). SOC was determined by the $\mathrm{K}_{2} \mathrm{Cr}_{2} \mathrm{O}_{7}-\mathrm{H}_{2} \mathrm{SO}_{4}$ oxidation method. Soil TN was analyzed using the Kjeldahl digestion procedure. Soil AN was determined using the continuous alkali-hydrolyzed reduction diffusion method. Soil AP was measured using the ultraviolet spectrophotometer method. Soil AK was determined by the flame photometer method [32]. SW and soil BD were determined by soil weight difference before and after oven-drying at $105^{\circ} \mathrm{C}$ for $8 \mathrm{~h}$ [20]. The SW contents and soil BD at the soil layer of $0-30 \mathrm{~cm}$ were calculated by the average contents of those at the $0-10,10-20$ and $20-30 \mathrm{~cm}$ layers.

\subsection{Data Analysis}

A one-way ANOVA was used to analyze the effects of rangeland desertification, sand stabilization treatments and dune topographic positions on each vegetation index and soil property. The general liner model was used to evaluate the effects of sand stabilization treatments, dune topographic locations and interactions of sand stabilization treatments $\times$ dune topographic locations on soil properties. The Least Significant Difference (LSD) procedure was applied to separate the means at a significance level of $p<0.05$. The results were expressed as mean values \pm standard error (SE). Pearson correlation analysis was applied to investigate the relationships among the soil properties. Data in this study were analyzed by the software of IBM SPSS Statistics 19.0 from Chicago, USA.

\section{Results}

\subsection{Features of Rangeland Desertification}

\subsubsection{Selected Vegetation Traits under Rangeland Desertification}

Plant coverage, biomass and height are important indicators for evaluating the extent of vegetation degradation and restoration [11]. As seen in Figure 3, with increasing rangeland desertification, the aboveground biomass, vegetation coverage and plant height decreased significantly $(p<0.05$, the SD was excluded in terms of the aboveground biomass and plant height). The aboveground biomass of the $\mathrm{SD}$ with lower vegetation coverage was larger than that of the MD, and showed no significant difference with that of the LD with a larger vegetation coverage. This was because the dried aboveground biomass of Ephedra minuta was larger than that of Carex moorcroftii and Kobresia setchwanensis, due to their physiological differences. The results indicate that desertification leads to thinner and sparser vegetation cover.
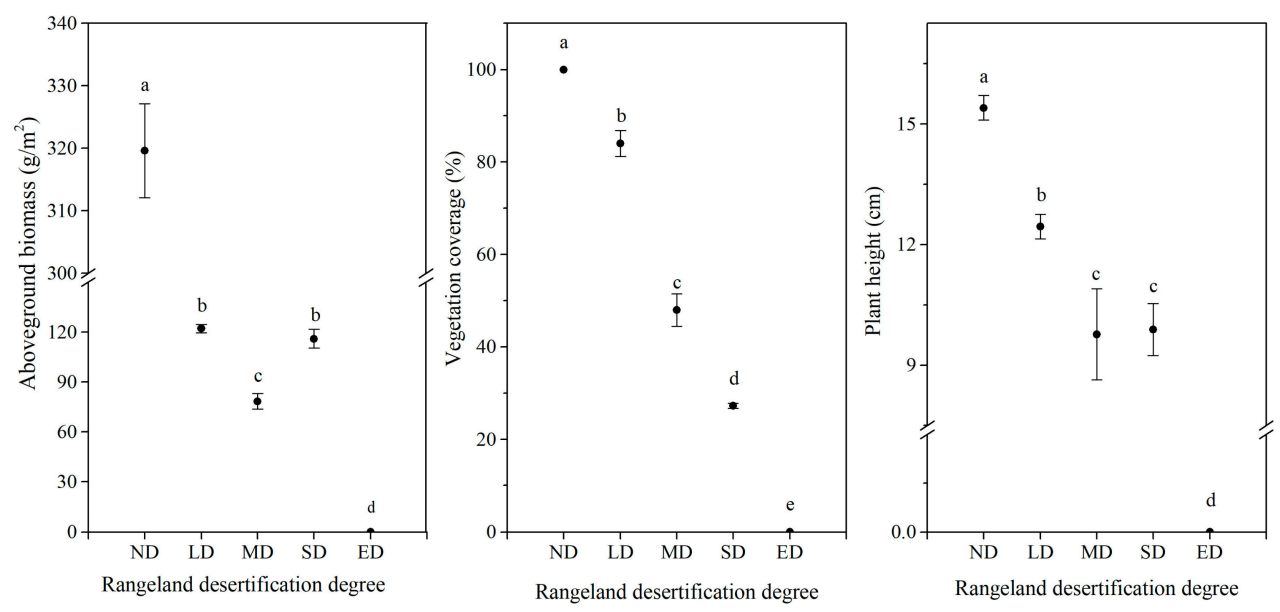

Figure 3. Selected vegetation indexes under five degrees of desertification. Vertical bars indicate standard errors of means $(n=5)$. Different letters indicate significant difference of each vegetation index among the desertification degrees at the 0.05 level. 


\subsubsection{Characteristics of Soil Particle Size Distributions under Rangeland Desertification}

With increasing desertification (from ND to ED) at each soil layer, the contents of clay and silt particles decreased significantly $(p<0.05)$, and the fine sand content increased significantly $(p<0.05)$. From LD to ED at each soil layer, the very fine sand content decreased significantly $(p<0.05)$, while the medium sand content increased significantly $(p<0.05)$ (Figure 4$)$. The characteristics of the soil PSDs showed that the clay, silt and very fine sand particles were selectively removed, while fine sand and medium sand particles were accumulated, indicating that soils were progressively coarsened with increasing desertification degree.
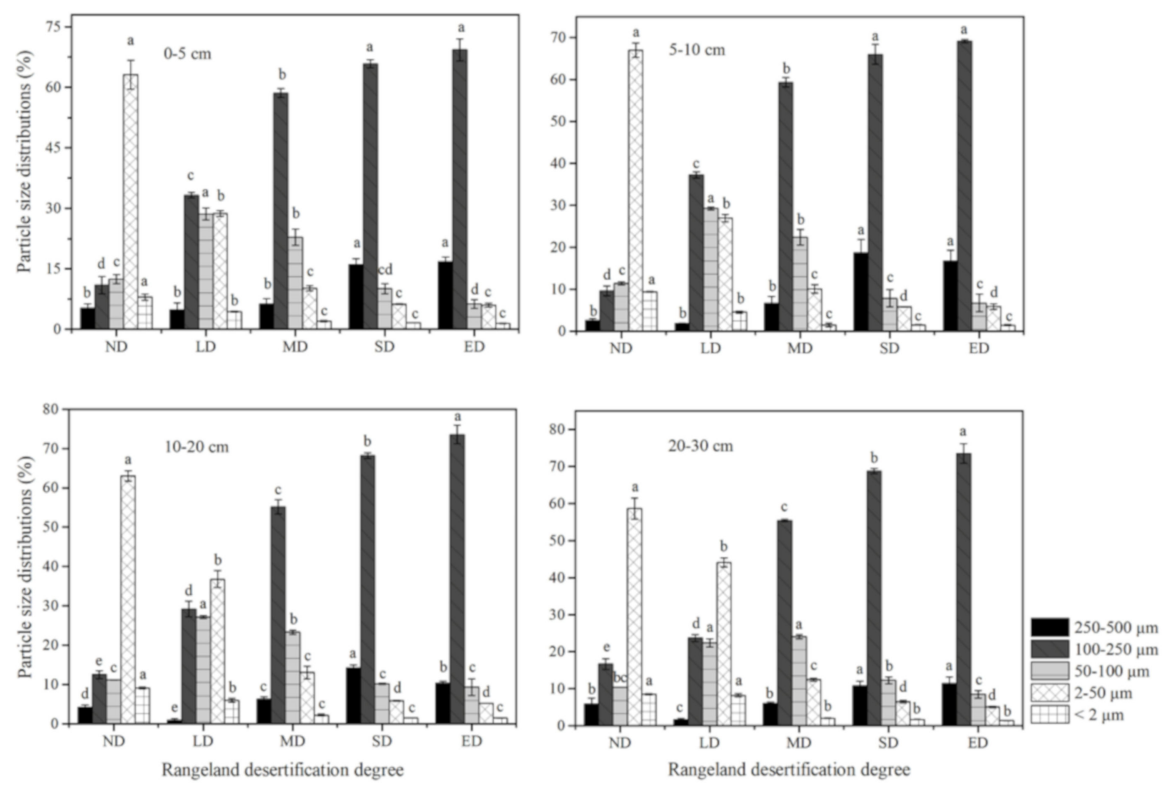

Figure 4. Variations in soil particle size distributions under five degrees of rangeland desertification. Vertical bars indicate standard errors of means $(n=3)$. Different letters in the same symbol indicate significant difference of the proportion of each particle size class among the desertification degrees at the 0.05 level.

\subsubsection{Selected Soil Properties under Rangeland Desertification}

Selected soil properties, including SOC, soil TN, AN, AP, AK, BD and SW at five degrees of rangeland desertification from the $0-30 \mathrm{~cm}$ soil layer, are shown in Table 2. The results indicated that with increasing desertification degree from ND to ED, the contents of SOC, TN, AN, AP, AK and SW decreased significantly $(p<0.05)$, while soil BD increased significantly $(p<0.05)$.

Table 2. Selected soil properties under five degrees of rangeland desertification within the 0-30 cm soil layer. Data are means \pm SE $(n=3)$.

\begin{tabular}{|c|c|c|c|c|c|c|c|}
\hline & SOC (g/kg) & TN (g/kg) & AN (mg/kg) & AP $(\mathrm{mg} / \mathrm{kg})$ & $\mathrm{AK}(\mathrm{mg} / \mathrm{kg})$ & $\mathrm{BD}\left(\mathrm{g} / \mathrm{cm}^{3}\right)$ & SW (\%) \\
\hline ND & $111.4 \pm 3.4^{\mathrm{a}}$ & $8.17 \pm 0.09^{a}$ & $936.5 \pm 70.9^{a}$ & $9.6 \pm 2.1^{\mathrm{a}}$ & $120.0 \pm 3.1^{a}$ & $0.71 \pm 0.03^{d}$ & $42.2 \pm 2.2^{a}$ \\
\hline LD & $23.1 \pm 0.8^{b}$ & $1.99 \pm 0.06^{b}$ & $228.7 \pm 4.3^{b}$ & $6.0 \pm 0.2^{b}$ & $115.2 \pm 5.6^{a}$ & 1.23 & $18.8 \pm 0.3^{b}$ \\
\hline MD & $6.0 \pm 0.4^{c}$ & $0.47 \pm 0.03^{c}$ & $65.7 \pm 5.5^{c}$ & $4.5 \pm 0.2^{b}$ & $63.7 \pm 2.5^{b}$ & $1.38 \pm 0.04^{b}$ & $6.8 \pm 0.5^{c}$ \\
\hline $\mathrm{SD}$ & $1.6 \pm 0.1^{c}$ & $0.21 \pm 0.01^{\mathrm{d}}$ & $15.8 \pm 0.1^{\mathrm{c}}$ & $3.4 \pm 0.1^{b}$ & $45.2 \pm 3.3^{c}$ & $1.57 \pm 0.04^{\mathrm{a}}$ & $4.1 \pm 0.1^{c}$ \\
\hline ED & $1.6 \pm 0.1^{\mathrm{c}}$ & $0.17 \pm 0^{d}$ & $8.8 \pm 0.2^{c}$ & $2.9 \pm 0.5^{b}$ & $39.1 \pm 1.7^{c}$ & $1.64 \pm 0.01^{\mathrm{a}}$ & $3.8 \pm 0.2^{\mathrm{c}}$ \\
\hline
\end{tabular}

Different letters in the same column indicate significant difference of each soil property among the desertification degrees at the 0.05 level. 


\subsection{Effectiveness of Treatments on Shifting Sand Dune Stabilization}

\subsubsection{Selected Vegetation Indexes under Sand Stabilization Treatments}

It is noted that the dominant plant species was found to be Elymus nutans at the middle and top locations, and Kobresia setchwanensis at the bottom location on the sand dune treated with CM. During the dune fixing process, Medicago sativa, artificially planted on the dune surface, died gradually and was replaced by Elymus nutans and Kobresia setchwanensis.

As seen from Table 3, along the slope of the dunes from the bottom, middle to top under the treatments of $\mathrm{CE}$ and $\mathrm{CM}$, the aboveground biomass and vegetation coverage decreased significantly $(p<0.05)$. The plant height under the CE treatment showed a decrease from the bottom to top. The plant height was $17 \mathrm{~cm}$ at the bottom location, where the dominant plant species was Kobresia setchwanensis, while the height was 33 and $25 \mathrm{~cm}$ at the middle and top positions of the sand dune treated with the CM, respectively, where the dominant species for both was Elymus nutans. The shrub height and canopy at the bottom and top locations were significantly larger than those at the middle position under the $S$ treatment. The results indicated that the $C E$ and $C M$ treatments greatly facilitated vegetation growth at the lower positions, while the $S$ treatment improved the plant growing state at the top and bottom locations of the sand dunes.

Table 3. Selected vegetation indexes at three topographic locations of the shifting dunes under three sand treatments. Data are means \pm SE $(n=5)$.

\begin{tabular}{ccccc}
\hline \multirow{2}{*}{$\begin{array}{c}\text { Sand Fixing } \\
\text { Treatments }\end{array}$} & Selected Vegetation Indexes & \multicolumn{2}{c}{ Topographic Locations of Sand Dunes } \\
\cline { 3 - 5 } & & BOT & MID & TOP \\
\hline \multirow{2}{*}{ CE } & Vegetation coverage $(\%)$ & $46 \pm 0.7^{\mathrm{a}}$ & $30 \pm 1.9^{\mathrm{b}}$ & $4 \pm 0.4^{\mathrm{c}}$ \\
& Plant height $(\mathrm{cm})$ & $35 \pm 1.3^{\mathrm{a}}$ & $25 \pm 2.5^{\mathrm{b}}$ & $22 \pm 0.6^{\mathrm{b}}$ \\
& Aboveground biomass $\left(\mathrm{g} / \mathrm{m}^{2}\right)$ & $71 \pm 2.5^{\mathrm{a}}$ & $30 \pm 2.6^{\mathrm{b}}$ & $6 \pm 0.6^{\mathrm{c}}$ \\
$\mathrm{CM}$ & Vegetation coverage $(\%)^{\mathrm{C}}$ & $47 \pm 3.1^{\mathrm{a}}$ & $30 \pm 1.0^{\mathrm{b}}$ & $6 \pm 0.4^{\mathrm{c}}$ \\
& Plant height $(\mathrm{cm})$ & $17 \pm 2.1^{\mathrm{b}}$ & $33 \pm 3.0^{\mathrm{a}}$ & $25 \pm 1.8^{\mathrm{ab}}$ \\
& Aboveground biomass $\left(\mathrm{g} / \mathrm{m}^{2}\right)$ & $79 \pm 1.8^{\mathrm{a}}$ & $32 \pm 3.2^{\mathrm{b}}$ & $7 \pm 1.3^{\mathrm{c}}$ \\
& Plant density (Plants $\left./ \mathrm{m}^{2}\right)$ & $0.32 \pm 0.02^{\mathrm{a}}$ & $0.35 \pm 0.01^{\mathrm{a}}$ & $0.30 \pm 0.01^{\mathrm{a}}$ \\
& Plant height $(\mathrm{cm})$ & $150 \pm 7.1^{\mathrm{a}}$ & $90 \pm 10.6^{\mathrm{b}}$ & $177 \pm 2.5^{\mathrm{a}}$ \\
& Plant canopy $(\mathrm{cm})$ & $148 \pm 13.7^{\mathrm{b}}$ & $90 \pm 9.1^{\mathrm{c}}$ & $209 \pm 5.4^{\mathrm{a}}$ \\
\hline
\end{tabular}

Different letters in the same row indicate significant difference of each vegetation index among the dune topographic locations at the 0.05 level.

\subsubsection{Characteristics of Soil Particle Size Distributions under Sand Stabilization Treatments}

Table 4 shows variations in soil particle size distributions on the mobile sand dunes at three positions under four treatments at $0-5 \mathrm{~cm}$ soil depth. The predominant particles were fine sand, ranging between $60 \%$ and $74 \%$ of total volume. Differences among the treatments in terms of the clay, silt, very fine sand, and medium sand contents were significant $(p<0.05)$, as seen from Table 5.

Compared to $\mathrm{CK}$, the clay and silt contents were higher under the treatments of $\mathrm{CE}$ and $\mathrm{CM}$, and the very fine sand contents were higher and the medium sand contents were lower under the $\mathrm{CE}, \mathrm{CM}$ and $\mathrm{S}$ treatments, indicating that these sand stabilization treatments contributed to a fine soil texture. The clay and silt contents were higher under the CE treatment than those under the $S$ treatment, indicating that the checkerboard protection planted with herbs was more prone to trapping fine soil particles.

Differences among the dune topographic positions in terms of the silt, very fine sand, and fine sand contents were significant (Table 5). The silt and very fine sand contents decreased, while the fine sand contents increased significantly along the slope from the bottom to top of the sand dunes treated with $\mathrm{CE}$ and $\mathrm{CM}$, indicating that soil particles were finer at the lower positions of the dunes. However, differences were not significant among the bottom, middle and top locations of the dunes under the CK and $S$ treatments for soil PSDs. 
Table 4. Proportion of soil particles (\%) within the $0-5 \mathrm{~cm}$ soil layer at three positions of the mobile sand dunes under four treatments. Data are means \pm SE $(n=3)$.

\begin{tabular}{|c|c|c|c|c|c|}
\hline \multirow{2}{*}{$\begin{array}{l}\text { Soil Particle Size } \\
\text { Classes }(\mu \mathrm{m})\end{array}$} & \multirow{2}{*}{ Treatments } & \multicolumn{3}{|c|}{ Positions of Sand Dunes } & \multirow[b]{2}{*}{ Mean } \\
\hline & & BOT & MID & TOP & \\
\hline \multirow[t]{4}{*}{$<2$} & CK & $1.1 \pm 0.0^{\mathrm{Cc}}$ & $1.4 \pm 0.0^{\mathrm{Ab}}$ & $1.2 \pm 0.0^{\mathrm{Ba}}$ & $1.2^{\mathrm{c}}$ \\
\hline & CE & $1.8 \pm 0.1^{\mathrm{Aab}}$ & $1.7 \pm 0.0^{\mathrm{Aa}}$ & $1.6 \pm 0.1 \mathrm{Aa}$ & $1.7^{\mathrm{a}}$ \\
\hline & $\mathrm{CM}$ & $1.9 \pm 0.1^{\mathrm{Aa}}$ & $1.3 \pm 0.1^{\mathrm{Bb}}$ & $\begin{array}{c}1.6 \pm 0.2 \\
\mathrm{ABa}\end{array}$ & $1.6^{\mathrm{ab}}$ \\
\hline & $\begin{array}{c}\text { S } \\
\text { Mean }\end{array}$ & $\begin{array}{c}1.5 \pm 0.1^{\mathrm{Ab}} \\
1.6^{\mathrm{A}}\end{array}$ & $\begin{array}{c}1.4 \pm 0.1^{\mathrm{Ab}} \\
1.4^{\mathrm{A}}\end{array}$ & $\begin{array}{c}1.3 \pm 0.1^{\mathrm{Aa}} \\
1.4^{\mathrm{A}}\end{array}$ & $1.4^{b c}$ \\
\hline \multirow[t]{5}{*}{$2-50$} & CK & $4 \pm 0.3^{\mathrm{Ac}}$ & $5 \pm 0.3^{\mathrm{Ab}}$ & $5 \pm 0.4 \mathrm{Aa}$ & $4.8^{c}$ \\
\hline & CE & $9 \pm 0.8^{\mathrm{Aa}}$ & $8 \pm 0.5^{\mathrm{ABa}}$ & $6 \pm 0.4^{\mathrm{Ba}}$ & $7.5^{\mathrm{a}}$ \\
\hline & $\mathrm{CM}$ & $8 \pm 0.2^{\mathrm{Aa}}$ & $5 \pm 0.2^{\mathrm{Bb}}$ & $6 \pm 1.0^{\mathrm{Ba}}$ & $6.3^{b}$ \\
\hline & S & $6 \pm 0.6^{\mathrm{Ab}}$ & $5 \pm 0.5^{\mathrm{Ab}}$ & $5 \pm 0.4^{\mathrm{Aa}}$ & $5.5^{b c}$ \\
\hline & Mean & $6.8^{\mathrm{A}}$ & $5.8^{\mathrm{B}}$ & $5.4^{\mathrm{B}}$ & \\
\hline \multirow[t]{5}{*}{ 50-100 } & CK & $6 \pm 0.5^{\mathrm{Ab}}$ & $3 \pm 1.5^{\mathrm{Ab}}$ & $4 \pm 1.6^{\mathrm{Ab}}$ & $4.5^{\mathrm{b}}$ \\
\hline & CE & $14 \pm 1.4^{\mathrm{ABa}}$ & $15 \pm 2.2 \mathrm{Aa}$ & $9 \pm 0.7 \mathrm{Bab}$ & $12.6^{\mathrm{a}}$ \\
\hline & $\mathrm{CM}$ & $16 \pm 1.5^{\mathrm{Aa}}$ & $10 \pm 1.5^{\mathrm{Ba}}$ & $7 \pm 1.0^{\mathrm{Bb}}$ & $11.0^{\mathrm{a}}$ \\
\hline & $\mathrm{S}$ & $12 \pm 1.9^{\mathrm{Aa}}$ & $10 \pm 0.7^{\mathrm{Aa}}$ & $11 \pm 1.0^{\mathrm{Aa}}$ & $11.0^{\mathrm{a}}$ \\
\hline & Mean & $11.7^{\mathrm{A}}$ & $9.7^{\mathrm{AB}}$ & $7.9^{\mathrm{B}}$ & \\
\hline \multirow[t]{5}{*}{$100-250$} & CK & $66 \pm 1.4^{\mathrm{Aa}}$ & $65 \pm 1.0^{\mathrm{Ab}}$ & $70 \pm 3.6^{\mathrm{Aa}}$ & $66.8^{a}$ \\
\hline & $\mathrm{CE}$ & $60 \pm 1.4^{\mathrm{Ca}}$ & $65 \pm 1.6^{\mathrm{Bb}}$ & $74 \pm 0.4^{\mathrm{Aa}}$ & $66.5^{a}$ \\
\hline & $\mathrm{CM}$ & $64 \pm 1.1^{\mathrm{Ba}}$ & $70 \pm 0.5^{\mathrm{Aa}}$ & $73 \pm 1.5^{\mathrm{Aa}}$ & $68.9^{a}$ \\
\hline & $\mathrm{S}$ & $65 \pm 3.3^{\mathrm{Aa}}$ & $69 \pm 0.9 \mathrm{Aa}$ & $71 \pm 1.3^{\mathrm{Aa}}$ & $68.3^{a}$ \\
\hline & Mean & $63.6^{\mathrm{C}}$ & $67.4^{\mathrm{B}}$ & $71.9^{\mathrm{A}}$ & \\
\hline \multirow[t]{5}{*}{$250-500$} & CK & $22 \pm 1.1 \mathrm{Aa}$ & $25 \pm 2.3^{\mathrm{Aa}}$ & $20 \pm 4.8^{\mathrm{Aa}}$ & $22.6^{a}$ \\
\hline & $\mathrm{CE}$ & $16 \pm 2.2 \mathrm{Aab}$ & $10 \pm 1.9 \mathrm{ABb}$ & $9 \pm 0.2^{\mathrm{Bb}}$ & $11.7^{b}$ \\
\hline & $\mathrm{CM}$ & $11 \pm 2.2^{\mathrm{Ab}}$ & $14 \pm 1.4^{\mathrm{Ab}}$ & $12 \pm 1.9 \mathrm{Aab}$ & $12.3^{b}$ \\
\hline & $\mathrm{S}$ & $16 \pm 4.3^{\mathrm{Aab}}$ & $14 \pm 0.9^{\mathrm{Ab}}$ & $11 \pm 1.9 \mathrm{Aab}$ & $13.6^{b}$ \\
\hline & Mean & $16.1^{\mathrm{A}}$ & $15.7^{\mathrm{A}}$ & $13.4^{\mathrm{A}}$ & \\
\hline
\end{tabular}

Different uppercase letters in the same row indicate significant difference among the dune topographic locations, and different lowercase letters in the same column indicate significant difference among the treatments at the 0.05 level, in terms of the proportion of each soil particle size class.

Table 5. F and $p$-values of soil particle size distributions analyzed by the general liner model, in which $\mathrm{T}, \mathrm{P}$ and $\mathrm{T} \times \mathrm{P}$ represent treatments, positions of sand dunes, and interactions of treatments $\times$ positions of sand dunes, respectively.

\begin{tabular}{ccccccccccc}
\hline & \multicolumn{2}{c}{$\mathbf{2 5 0 - 5 0 0} \boldsymbol{\mu m}$} & \multicolumn{2}{c}{$\mathbf{1 0 0 - 2 5 0} \boldsymbol{\mu m}$} & \multicolumn{2}{c}{$\mathbf{5 0 - 1 0 0} \boldsymbol{\mu m}$} & \multicolumn{2}{c}{$\mathbf{2 - 5 0} \boldsymbol{\mu m}$} & \multicolumn{2}{c}{$<\mathbf{\mu m}$} \\
\cline { 2 - 11 } & F-Value & $\boldsymbol{p}$-Value & F-Value & $\boldsymbol{p}$-Value & F-Value & $\boldsymbol{p}$-Value & F-Value & $\boldsymbol{p}$-Value & F-Value & $\boldsymbol{p}$-Value \\
\hline $\mathrm{T}$ & 13.014 & $<0.001$ & 1.361 & 0.279 & 19.94 & $<0.001$ & 15.51 & $<0.001$ & 12.22 & $<0.001$ \\
$\mathrm{P}$ & 1.465 & 0.251 & 22.87 & $<0.001$ & 7.8 & 0.002 & 8.31 & 0.002 & 2.94 & 0.072 \\
$\mathrm{~T} \times \mathrm{P}$ & 0.865 & 0.534 & 2 & 0.105 & 2.8 & 0.033 & 3.26 & 0.017 & 4.34 & 0.004 \\
\hline
\end{tabular}

\subsubsection{Selected Soil Properties under Sand Fixing Treatments}

Differences among the treatments of $\mathrm{CK}, \mathrm{CE}, \mathrm{CM}$ and $\mathrm{S}$, in terms of each soil property, were significant $(p<0.05)$, as seen from Table 6. The SOC, AN and AK contents under the treatments of CE, $\mathrm{CM}$ and $\mathrm{S}$, the TN contents under the $\mathrm{CE}$ and $\mathrm{CM}$, and the AP contents under the $\mathrm{CE}$ and $\mathrm{S}$, were higher compared to CK (Figure 5). The SOC and TN contents under the CE and CM treatments were higher than those under the $S$ treatment, and differences were significant between the CM and $S$. The AK content under the $\mathrm{CM}$ was significantly higher than that under the $\mathrm{S}$ treatment. The results indicated that the three treatments, especially CM, contributed to improving soil properties after stabilizing the mobile sand dunes for 5 years. 
Table 6. F and $p$-values of selected soil properties analyzed by the general linear model, in which T, $\mathrm{P}$ and $\mathrm{T} \times \mathrm{P}$ represent treatments, positions of sand dunes, and interactions of treatments $\times$ positions of sand dunes, respectively.

\begin{tabular}{ccccccccccc}
\hline & SOC & & TN & & AN & \multicolumn{3}{c}{ AP } & \multicolumn{3}{c}{ AK } \\
\hline & F-Value & $\boldsymbol{p}$-Value & F-Value & $\boldsymbol{p}$-Value & F-Value & $\boldsymbol{p}$-Value & F-Value & $\boldsymbol{p}$-Value & F-Value & $\boldsymbol{p}$-Value \\
\hline $\mathrm{T}$ & 14.459 & $<0.001$ & 3.988 & 0.019 & 11.359 & $<0.001$ & 4.086 & 0.018 & 24.721 & $<0.001$ \\
$\mathrm{P}$ & 6.626 & 0.005 & 15.775 & $<0.001$ & 21.894 & $<0.001$ & 2.414 & 0.111 & 2.211 & 0.131 \\
$\mathrm{~T} \times \mathrm{P}$ & 1.889 & 0.124 & 7.300 & $<0.001$ & 6.989 & $<0.001$ & 1.227 & 0.327 & 7.711 & $<0.001$ \\
\hline
\end{tabular}
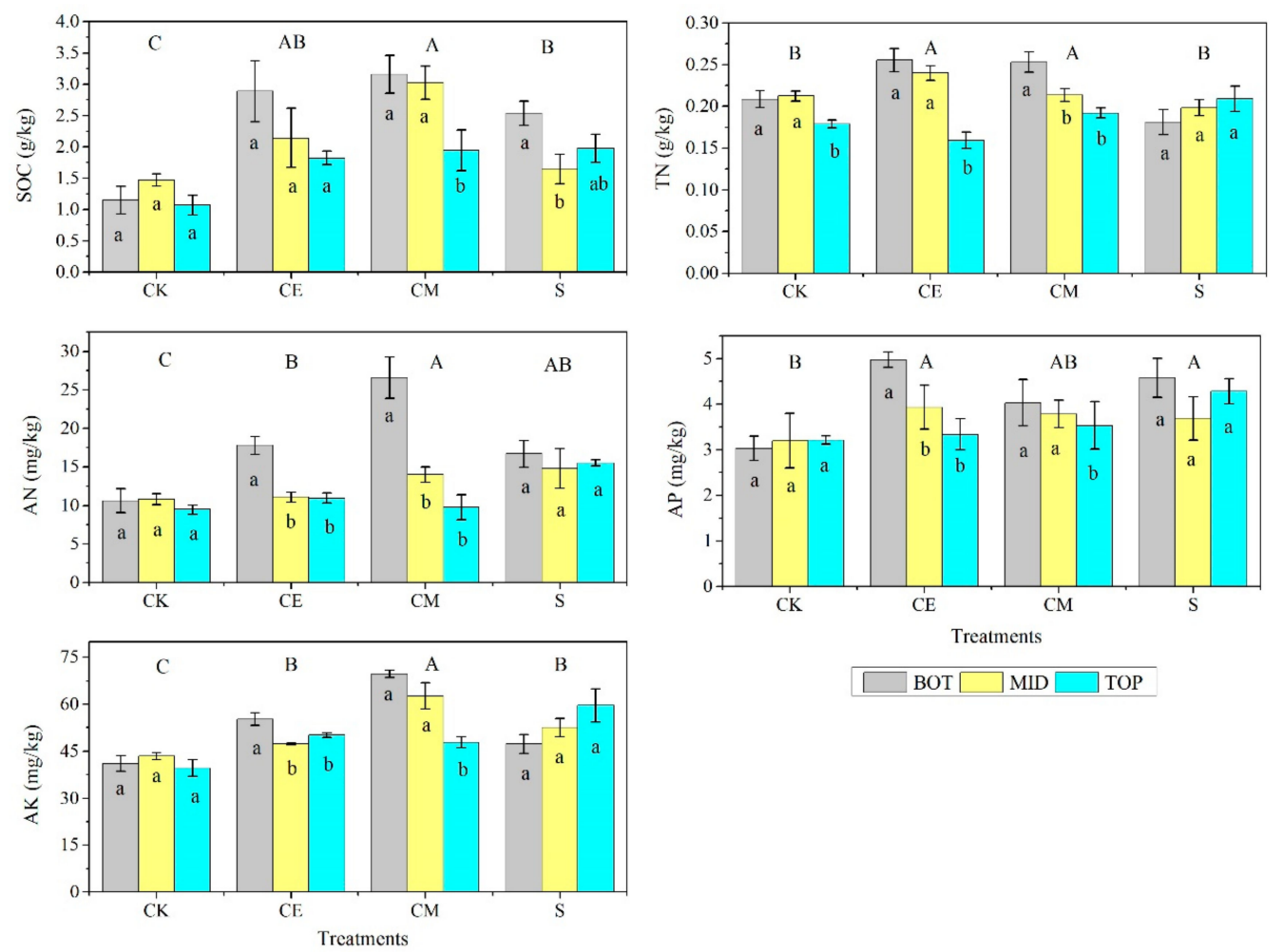

Figure 5. Selected soil properties within the $0-5 \mathrm{~cm}$ soil layer at three positions of the mobile sand dunes under four treatments. Different lowercase letters indicate significant difference at the 0.05 level among the positions under the same treatment, and different uppercase letters indicate significant difference at the 0.05 level among the treatments, in terms of each soil property.

Differences among the dune positions were significant $(p<0.05)$, in terms of SOC, TN and AN contents (Table 6). Results showed that the contents of SOC, TN and AN were higher at the bottom locations than those at the top locations (data not displayed). As seen from Figure 5, the contents of the five soil indicators under the CE and CM treatments were decreasing, along the slope from the bottom to top of the sand dunes. However, differences were generally not significant among the dune positions under the $\mathrm{CK}$ and $\mathrm{S}$ treatments.

\subsection{Correlations among Soil Properties}

Relationships among the sand, silt and clay contents and selected soil properties from sample sites under desertification and stabilization are shown in Table 7. As seen, for sample sites under desertification, the SOC, TN, AN, AP, AK and SW contents were in significant positive correlation with the clay and silt contents and showed a very strong negative correlation with the sand contents, with coefficients ranging from 0.92 to 1 . The BD were negatively correlated with the clay and silt contents, and positively correlated with the sand contents. The SOC, TN, AN, AP and AK contents had a strong 
positive correlation with the SW contents, but had a negative correlation with soil BD. In addition, the SW contents were significantly negatively correlated with soil BD.

Table 7. Pearson correlation coefficients among selected soil properties under rangeland desertification and sand stabilization treatments.

\begin{tabular}{|c|c|c|c|c|c|c|c|c|c|c|}
\hline & Sand & Silt & Clay & SOC & TN & AN & AP & AK & BD & SW \\
\hline \multicolumn{11}{|c|}{ Sampling sites under rangeland desertification $(n=5)$} \\
\hline Sand & 1 & & & & & & & & & \\
\hline Silt & $-1.00 * *$ & 1 & & & & & & & & \\
\hline Clay & $-1.00^{* *}$ & $0.99 * *$ & 1 & & & & & & & \\
\hline SOC & $-0.95 *$ & $0.95 *$ & $0.92 *$ & 1 & & & & & & \\
\hline $\mathrm{TN}$ & $-0.96^{* *}$ & $0.96^{* *}$ & $0.93 *$ & $1.00 * *$ & 1 & & & & & \\
\hline AN & $-0.96 * *$ & $0.97 * *$ & $0.94 *$ & $1.00 * *$ & $1.00 * *$ & 1 & & & & \\
\hline $\mathrm{AP}$ & $-0.99 * *$ & $0.99 * *$ & $0.97 * *$ & $0.96^{* *}$ & $0.97 * *$ & $0.97 * *$ & 1 & & & \\
\hline AK & $-0.92 *$ & $0.92 *$ & 0.95 * & 0.76 & 0.78 & 0.79 & $0.90 *$ & 1 & & \\
\hline $\mathrm{BD}$ & $0.98 * *$ & $-0.98 * *$ & $-0.96 *$ & $-0.96 *$ & $-0.96 * *$ & $-0.97 * *$ & $-1.00 * *$ & $-0.89 *$ & 1 & \\
\hline SW & $-0.99 * *$ & $0.99 * *$ & $0.98^{* *}$ & $0.98 * *$ & $0.99 * *$ & $0.99 * *$ & $0.99 * *$ & 0.87 & $-0.98^{* *}$ & 1 \\
\hline \multicolumn{11}{|c|}{ Sampling sites under the sand stabilization treatments $(n=12)$} \\
\hline Sand & 1 & & & & & & & & & \\
\hline Silt & $-0.99 * *$ & 1 & & & & & & & & \\
\hline Clay & $-0.92 * *$ & $0.91 * *$ & 1 & & & & & & & \\
\hline SOC & $-0.69 *$ & $0.69 *$ & $0.63 *$ & 1 & & & & & & \\
\hline $\mathrm{TN}$ & $-0.64 *$ & $0.66^{*}$ & 0.45 & 0.55 & 1 & & & & & \\
\hline AN & $-0.59 *$ & 0.57 & 0.56 & $0.75^{* *}$ & 0.57 & 1 & & & & \\
\hline $\mathrm{AP}$ & $-0.69 *$ & $0.69 *$ & 0.55 & $0.73^{* *}$ & 0.47 & $0.61 *$ & 1 & & & \\
\hline $\mathrm{AK}$ & -0.41 & 0.42 & 0.44 & $0.81^{* *}$ & 0.50 & $0.81^{* *}$ & 0.50 & 1 & & \\
\hline
\end{tabular}

Compared to the sampling sites under desertification, weaker relationships were found among the selected soil properties and the sand, silt and clay contents under the sand fixing treatments, with coefficients ranging from 0.41 to 0.81 . The SOC, TN, AN and AP contents showed strong negative correlations with the sand contents and showed positive correlations with the silt and clay contents.

\section{Discussion}

\subsection{Characteristics of Rangeland Desertification}

Desertification resulted in decreased vegetation coverage, plant height and aboveground biomass. Li et al. [4] reported that in semi-arid steppe on the QTP, rangeland vegetation coverage decreased continuously until desertification occurred. Overgrazing, one of the main driving factors for rangeland desertification, depletes soil nutrients continuously, which in turn affects vegetation coverage and biomass adversely [4]. With decreasing vegetation coverage, bare soil areas increased, especially during the winter and spring when vegetation coverage is lower, soils are more easily exposed to windy environments without protection, and thus, fine soil particles such as clay and silt are preferentially eroded and removed by wind [33,34], resulting in coarser soil textures [35].

The present study showed that with increasing desertification degree, the SOC, TN, AN, AP, AK, and SW contents decreased significantly, while soil BD increased significantly, leading to a poor desert soil environment. The Pearson correlation analysis showed that the SOC, TN, AN, AP, AK and SW contents were in significant positive correlation with the clay and silt contents, and showed a very strong negative correlation with the sand contents. Previous studies have shown that the losses of SOC, TN and other soil nutrients were mainly due to the removal of fine particles (silts and clays) induced by wind erosion in dry land [21,35-38]. Compared to sand particles, silt and clay particles had higher capacity for holding soil water and nutrients [39-41]. In addition, decreased vegetation biomass and lower litter decomposition caused the reduction input of soil organic matters, thus, soil nutrients decreased accordingly [42]. Soil BD was negatively correlated with the clay and silt contents, 
and was positively correlated with the sand contents, mainly due to the reduction in soil organic matter contents and pore space [43-45].

\subsection{Short-Term Effectiveness of the Treatments on Fixing Mobile Sand Dunes}

The aboveground biomass and vegetation coverage decreased significantly from the bottom to top of the sand dunes under the $\mathrm{CE}$ and $\mathrm{CM}$ treatments, indicating that the checkerboard protection planted with herbs could facilitate vegetation restoration better at the lower parts of the dunes more than that at the upper parts. After the checkerboard barriers were established on the mobile sand dunes, the near-surface wind speed decreased and the sediment transport reduced, thus the shifting dune surface gradually stabilized, forming an environment with a weakened wind strength and providing favorable conditions for plants $[46,47]$. However, wind speed increases with increasing dune height, therefore, the upper parts of sand dunes have higher wind power, resulting in higher mobility of sand particles, stronger wind erosion and deposition than the lower parts. Thus, herbaceous plants and their seeds are more difficult to fix on the dune surfaces at the upper parts and were more easily blown away by wind erosion and buried by the accumulated sand particles [14]. In addition, the frequent windy days last from November to April when vegetation has stopped growing, and during the same period there was lower precipitation across the study area. This natural phenomenon causes stronger aeolian movement, due to the lower vegetation coverage and drier sandy soil environment on dunes, which in turn adversely affects vegetation growing environments.

During the plant restoration process, the alien plant species Medicago sativa was replaced naturally by two native plant species, mainly because the native species are best adapted to the local environments and survived. Therefore, native plant species was suggested to be used, when fixing mobile dunes.

The height and canopy of shrubs, at the middle location of the sand dunes under the shrub vegetation planting treatment, were significantly lower than those at the top and bottom locations. It was noted that the top site of the sand dune planted with shrub vegetation was less steep and flatter than the middle and bottom sites. Feng et al. [48] reported that wind erosion showed an increase with increasing surface slopes. Therefore, vegetation is more prone to wind erosion and deposition and was slower to restore at the middle sites with a steep slope. Some literature [31,49] also suggests that vegetation restoration is more rapid on flat sandy land and lower parts of sand dunes, while it takes longer on upper and steeper parts of the dunes.

Soil particles were finer, and nutrients had been improved under the CE, CM and S treatments, compared to the bare sand dune. The checkerboard treatment planted with herbs, and the shrub planting treatment without checkerboards contributed to trapping wind-blown fine particles (such as the very fine sand, silt, and clay particles), by decreasing surface wind speed and protecting soil particles from further entrapment [47]. This is very important for sand fixation, because fine particles adhering to each other may enhance the stability of the sand dune surface [50]. During the vegetation restoration process on dunes, vegetation increased soil organic matter input and soil water holding capacity, and reduced the losses of nutrients by wind erosion, thereby contributing to the accumulation of soil nutrients $[16,19,39]$, which in turn favored vegetation restoration. In addition, the dead Medicago sativa on dunes under the CM treatment led to higher input of organic matters into soils.

The lower locations of the dunes under the checkerboard protection planted with herbs, contributed to improving soil nutrients and textures more than the higher locations did, mainly due to the larger vegetation coverage, higher soil water contents, and lower wind speed at the lower locations. As vegetation coverage decreased at the upper parts of dunes, sediment flux increased, and fine particles were more prone to removal by wind erosion, so soil textures were coarser, and nutrients were lower $[47,51]$. However, differences of soil properties were not significant among the dune positions under the $S$ treatment, probably because shrubs were less efficient at trapping fine particles, and sand particles could move more easily due to the reduced roughness at the dune surface, relative to the checkboard protection planted with herbs [15]. This also explained why the checkboard protection planted with herbs improved soil properties on the dune surfaces slightly more than the shrub planting 
treatment alone did. Therefore, it is useful to establish the checkboard protection before applying the shrub planting method.

The CM, CE and $S$ treatments contributed to trapping fine particles and improving soil nutrients on the dune uppermost surface and were effective at stabilizing the mobile dunes. Vegetation, at the top, middle and bottom locations of the shifting sand dunes under the CE and CM treatments, was restored to the levels of the ED, SD and MD sites, respectively. Meanwhile, soil SOC, TN and AN content on the dunes were restored to the level of the SD site, indicating slower soil restoration processes compared with the vegetation restoration. Miao et al. [22] also reported that soil restoration had a lag effect relative to vegetation restoration in degraded grasslands. Generally, the ecologically harsh environments (including low temperatures, windy environments, very low percentages of silt and clay, limited soil moisture, and infertile sandy soil) make vegetation and soil recovery on shifting sand dunes very slow, especially in alpine rangelands with a high elevation and cold climate. As some literature suggests [30,31,49], it would take a longer time for vegetation and soil properties to be satisfactorily restored on mobile sand dunes in order to sustain more intensive land use.

\section{Conclusions}

In this study, we assessed the features of desertification and short-term ( 5 years) effectiveness of three treatments on fixing mobile sand dunes on the windward slope by monitoring selected vegetation indexes (including aboveground biomass, vegetation coverage and plant height for herbs, and plant density, height and canopy for shrubs) and soil properties (including soil particle size distributions, soil $\mathrm{BD}, \mathrm{SW}, \mathrm{SOC}, \mathrm{TN}, \mathrm{AN}, \mathrm{AP}$ and $\mathrm{AK}$ ) in an alpine rangeland with an elevation of $3500 \mathrm{~m}$ on the eastern QTP.

With increasing desertification degree, aboveground biomass, vegetation coverage and plant height were significantly decreased. Soil textures were coarsened with the loss of clay, silt and very fine sand particles, and the accumulation of fine sand and medium sand particles; soil nutrients, (including SOC, TN, AN, AP and AK) reduced, soil water contents decreased, and soil BD increased significantly under increasing rangeland desertification.

The checkerboard protection planted with Elymus nutans and Medicago sativa (herbs), and the Salix oritrepha (shrub) planting method without checkerboards, are effective in restoring vegetation and improving soil textures as well as nutrients on the mobile sand dune surface. The checkerboard protection planted with herbs performed slightly better in improving soil properties than the shrub planting treatment alone. Aboveground biomass, vegetation coverage and plant height decreased, soil textures became coarsened, and soil nutrients decreased along the slope from the bottom, middle to the top locations of the dunes under the checkerboard protection planted with herbs. The shrub planting treatment improved the plant height and canopy size more at the top and bottom locations so than the middle location of the dunes, but had little effect on soil textures and nutrients on the three dune topographic locations. Native plant species are proposed for restoring vegetation in desertified rangelands, and a longer time period would be required for vegetation and soils to be restored sufficiently to sustain more intensive land use.

Author Contributions: Conceptualization, X.F. and J.Q.; methodology, X.F. and L.T.; investigation, X.F. and Q.F.; data curation, X.F., J.Q., and Q.F.; writing—original draft preparation, X.F. and J.Q.; writing-review and editing, J.Q.; visualization, Q.F., L.T., and Z.A.; supervision, J.Q.; project administration, J.Q.; funding acquisition, J.Q.

Funding: This research was funded by National Key Research and Development Program of China: 2017YFC0504804.

Acknowledgments: This study was financially supported by The National Key Research and Development Program of China (grant No. 2017YFC0504804).

Conflicts of Interest: The authors declare no conflict of interest. 


\section{Abbreviations}

$\begin{array}{ll}\text { QTP } & \text { Qinghai-Tibet Plateau } \\ \text { ND } & \text { None desertified rangeland } \\ \text { LD } & \text { Lightly desertified rangeland } \\ \text { MD } & \text { Medium desertified rangeland } \\ \text { SD } & \text { Severely desertified rangeland } \\ \text { ED } & \text { Extremely desertified rangeland } \\ \text { CE } & \text { The treatment of checkerboard protection planted with Elymus nutans } \\ \text { CM } & \text { The treatment of checkerboard protection planted with Medicago sativa } \\ \text { S } & \text { The treatment of shrub vegetation planting method } \\ \text { CK } & \text { The treatment of control } \\ \text { BD } & \text { Soil bulk density } \\ \text { SW } & \text { Soil water content } \\ \text { PSDs } & \text { Soil particle size distributions }\end{array}$

\section{References}

1. Wang, T.; Chang, X.L.; Chen, G.T.; Chen, H.Z.; Chen, L.H.; Gao, Q.Z.; Fan, S.Y.; He, X.D.; Han, Z.W.; Li, B.S.; et al. Dertification and Aeolian Desertification in China; Science Press: Beijing, China, 2011; pp. 12-14.

2. Wang, T. Aeolian desertification and its control in Northern China. Int. Soil Water Conserv. Res. 2014, 2, $34-41$.

3. Zhang, C.L.; Li, Q.; Shen, Y.P.; Zhou, N.; Wang, X.S.; Li, J.; Jia, W.R. Monitoring of aeolian desertification on the Qinghai-Tibet Plateau from the 1970s to 2015 using Landsat images. Sci. Total Environ. 2018, 619, 1648-1659. [CrossRef] [PubMed]

4. Li, X.L.; Gao, J.; Brierley, G.; Qiao, Y.M.; Zhang, J.; Yang, Y.W. Rangeland degradation on the Qinghai-Tibet plateau: Implications for rehabilitation. Land Degrad. Dev. 2013, 24, 72-80. [CrossRef]

5. Costantini, E.A.; Branquinho, C.; Nunes, A.; Schwilch, G.; Stavi, I.; Valdecantos, A.; Zucca, C. Soil indicators to assess the effectiveness of restoration strategies in dryland ecosystems. Solid Earth 2016, 7, 397-414. [CrossRef]

6. Dong, Z.B.; Hu, G.Y.; Yan, C.Z.; Wang, W.L.; Lu, J.F. Aeolian desertification and its causes in the Zoige Plateau of China's Qinghai-Tibetan Plateau. Environ Earth Sci. 2010, 59, 1731-1740. [CrossRef]

7. Dong, Z.B.; Hu, G.Y.; Qian, G.Q.; Lu, J.F.; Zhang, Z.C.; Luo, W.Y.; Lyu, P. High-Altitude Aeolian Research on the Tibetan Plateau. Rev. Geophys. 2017, 55, 864-901. [CrossRef]

8. Hu, G.Y.; Dong, Z.B.; Lu, J.F.; Yan, C.Z. The developmental trend and influencing factors of aeolian desertification in the Zoige Basin, eastern Qinghai-Tibet Plateau. Aeolian Res. 2015, 19, 275-281. [CrossRef]

9. Hu, G.Y.; Jin, H.J.; Dong, Z.B.; Lu, J.F.; Yan, C.Z. Driving forces of aeolian desertification in the source region of the Yellow River: 1975-2005. Environ. Earth Sci. 2013, 70, 3245-3254. [CrossRef]

10. Xie, S.; Qu, J.; Xu, X.; Pang, Y. Interactions between freeze-thaw actions, wind erosion desertification, and permafrost in the Qinghai-Tibet Plateau. Nat. Hazards 2017, 85, 829-850. [CrossRef]

11. Zhang, T.H.; Zhao, H.L.; Li, S.G.; Li, F.R.; Shirato, Y.; Ohkuro, T.; Taniyama, I. A comparison of different measures for stabilizing moving sand dunes in the Horqin Sandy Land of Inner Mongolia, China. J. Arid Environ. 2004, 58, 203-214. [CrossRef]

12. Wang, T.; Xue, X.; Zhou, L.; Guo, J. Combating aeolian desertification in northern China. Land Degrad. Dev. 2015, 26, 118-132. [CrossRef]

13. Tsoar, H. Sand dunes mobility and stability in relation to climate. Physica A 2005, 357, 50-56. [CrossRef]

14. Liu, Z.M.; Zhao, W.Z. Shifting-sand control in central Tibet. AMBIO 2001, 30, 376-381. [PubMed]

15. Li, Y.; Cui, J.; Zhang, T.; Okuro, T.; Drake, S. Effectiveness of sand-fixing measures on desert land restoration in Kerqin Sandy Land, northern China. Ecol. Eng. 2009, 35, 118-127. [CrossRef]

16. Li, X.R.; Xiao, H.L.; Zhang, J.G.; Wang, X.P. Long-term ecosystem effects of sand-binding vegetation in the Tengger Desert, northern China. Restor. Ecol. 2004, 12, 376-390. [CrossRef]

17. Su, Y.Z.; Zhang, T.H.; Li, Y.L.; Wang, F. Changes in soil properties after establishment of Artemisia halodendron and Caragana microphylla on shifting sand dunes in semiarid Horqin Sandy Land, Northern China. Environ. Manag. 2005, 36, 272-281. [CrossRef] 
18. Zhao, H.L.; Zhou, R.L.; Su, Y.Z.; Zhang, H.; Zhao, L.Y.; Drake, S. Shrub facilitation of desert land restoration in the Horqin Sand Land of Inner Mongolia. Ecol. Eng. 2007, 31, 1-8. [CrossRef]

19. Li, Y.; Li, Z.; Wang, Z.; Wang, W.; Jia, Y.; Tian, S. Impacts of artificially planted vegetation on the ecological restoration of movable sand dunes in the Mugetan Desert, northeastern Qinghai-Tibet Plateau. Int. J. Sediment Res. 2017, 32, 277-287. [CrossRef]

20. Zhang, Y.; Zhao, W. Vegetation and soil property response of short-time fencing in temperate desert of the Hexi Corridor, northwestern China. Catena 2015, 133, 43-51. [CrossRef]

21. Ebrahimi, M.; Khosravi, H.; Rigi, M. Short-term grazing exclusion from heavy livestock rangelands affects vegetation cover and soil properties in natural ecosystems of southeastern Iran. Ecol. Eng. 2016, 95, 10-18. [CrossRef]

22. Miao, R.; Jiang, D.; Musa, A.; Zhou, Q.; Guo, M.; Wang, Y. Effectiveness of shrub planting and grazing exclusion on degraded sandy grassland restoration in Horqin sandy land in Inner Mongolia. Ecol. Eng. 2015, 74, 164-173. [CrossRef]

23. Hu, Y.F.; Peng, J.J.; Yuan, S.; Shu, X.Y.; Jiang, S.L.; Pu, Q.; Ma, K.Y.; Yuan, C.M.; Chen, G.D.; Xiao, H.H. Influence of ecological restoration on vegetation and soil microbiological properties in Alpine-cold semi-humid desertified land. Ecol. Eng. 2016, 94, 88-94. [CrossRef]

24. Mohawesh, Y.; Taimeh, A.; Ziadat, F. Effects of land use changes and soil conservation intervention on soil properties as indicators for land degradation under a Mediterranean climate. Solid Earth 2015, 6, 857-868. [CrossRef]

25. Hoppe, F.; Kyzy, T.Z.; Usupbaev, A.; Schickhoff, U. Rangeland degradation assessment in Kyrgyzstan: Vegetation and soils as indicators of grazing pressure in Naryn Oblast. J. Mt. Sci. 2016, 13, 1567-1583. [CrossRef]

26. Pulido, M.; Schnabel, S.; Contador, J.F.L.; Lozano-Parra, J.; Gómez-Gutiérrez, Á. Selecting indicators for assessing soil quality and degradation in rangelands of Extremadura (SW Spain). Ecol. Indic. 2017, 74, 49-61. [CrossRef]

27. Yuan, Z.Q.; Jiang, X.J.; Liu, G.J.; Jin, H.J.; Chen, J.; Wu, Q.B. Responses of soil organic carbon and nutrient stocks to human-induced grassland degradation in a Tibetan alpine meadow. Catena 2019, 178, 40-48. [CrossRef]

28. Carpenter, S.R.; Turner, M.G. Hares and tortoises: Interactions of fast and slow variablesin ecosystems. Ecosystems 2000, 3, 495-497. [CrossRef]

29. Wang, T.; Chang, X.L.; Chen, G.T.; Chen, H.Z.; Chen, L.H.; Gao, Q.Z.; Fan, S.Y.; He, X.D.; Han, Z.W.; Li, B.S.; et al. Dertification and Aeolian Desertification in China; Science Press: Beijing, China, 2011; pp. 121-124.

30. Belnap, J. Surface disturbances: Their role in accelerating desertification. Environ. Monit. Assess. 1995, 37, 39-57. [CrossRef]

31. Shirato, Y.; Zhang, T.H.; Ohkuro, T.; Fujiwara, H.; Taniyama, I. Changes in Topographical Features and Soil Properties after Exclosure Combined with Sand-Fixing Measures in Horqin Sandy Land, Northern China. Soil Sci. Plant Nutr. 2005, 51, 61-68. [CrossRef]

32. Feng, X.; Qu, J.; Tan, L.; Fan, Q.; Niu, Q. Fractal features of sandy soil particle-size distributions during the rangeland desertification process on the eastern Qinghai-Tibet Plateau. J. Soils Sediments 2019, 1-14. [CrossRef]

33. Wang, X.M.; Lang, L.L.; Yan, P.; Wang, G.T.; Li, H.; Ma, W.Y.; Hua, T. Aeolian processes and their effect on sandy desertification of the Qinghai-Tibet Plateau: A wind tunnel experiment. Soil Tillage Res. 2016, 158, 67-75. [CrossRef]

34. Yan, Y.C.; Wang, X.; Guo, Z.J.; Chen, J.Q.; Xin, X.P.; Xu, D.W.; Yan, R.R.; Chen, B.R.; Xu, L.J. Influence of wind erosion on dry aggregate size distribution and nutrients in three steppe soils in northern China. Catena 2018, 170, 159-168. [CrossRef]

35. Su, Y.Z.; Zhao, H.L.; Zhao, W.Z.; Zhang, T.H. Fractal features of soil particle size distribution and the implication for indicating desertification. Geoderma 2004, 122, 43-49. [CrossRef]

36. Wang, X.; Lang, L.; Hua, T.; Li, H.; Zhang, C.; Ma, W. Effects of aeolian processes on soil nutrient loss in the Gonghe Basin, Qinghai-Tibet Plateau: An experimental study. J. Soils Sediments 2018, 18, 229-238. [CrossRef]

37. Deng, J.F.; Li, J.H.; Deng, G.; Zhu, H.Y.; Zhang, R.H. Fractal scaling of particle-size distribution and associations with soil properties of Mongolian pine plantations in the Mu Us Desert, China. Sci. Rep. 2017, 7, 6742. [CrossRef] [PubMed] 
38. Jin, Z.; Dong, Y.S.; Qi, Y.C.; Liu, W.G.; An, Z.S. Characterizing variations in soil particle-size distribution along a grass-desert shrub transition in the ordos plateau of Inner Mongolia, China. Land Degrad. Dev. 2013, 24, 141-146. [CrossRef]

39. Zhao, W.J.; Cui, Z.; Ma, H. Fractal features of soil particle-size distributions and their relationships with soil properties in gravel-mulched fields. Arab. J. Geosci. 2017, 10, 211. [CrossRef]

40. Liu, X.; Zhang, G.; Heathman, G.C.; Wang, Y.; Huang, C.H. Fractal features of soil particle-size distribution as affected by plant communities in the forested region of Mountain Yimeng, China. Geoderma 2009, 154, 123-130. [CrossRef]

41. Gao, G.L.; Ding, G.D.; Zhao, Y.Y.; Wu, B.; Zhang, Y.Q.; Qin, S.G.; Bao, Y.F.; Yu, M.H.; Liu, Y.D. Fractal approach to estimating changes in soil properties following the establishment of Caragana korshinskii shelterbelts in Ningxia, NW China. Ecol. Indic. 2014, 43, 236-243. [CrossRef]

42. Albaladejo, J.; Martinez-Mena, M.; Roldan, A.; Castillo, V. Soil degradation and desertification induced by vegetation removal in a semiarid environment. Soil Use Manag. 1998, 14, 1-5. [CrossRef]

43. Heuscher, S.A.; Brandt, C.C.; Jardine, P.M. Using soil physical and chemical properties to estimate bulk density. Soil Sci. Soc. Am. J. 2005, 69, 51-56.

44. Yang, F.; Zhang, G.L.; Yang, J.L.; Li, D.C.; Zhao, Y.G.; Liu, F.; Yang, R.M.; Yang, F. Organic matter controls of soil water retention in an alpine grassland and its significance for hydrological processes. J. Hydrol. 2014, 519, 3086-3093. [CrossRef]

45. Keller, T.; Håkansson, I. Estimation of reference bulk density from soil particle size distribution and soil organic matter content. Geoderma 2010, 154, 398-406. [CrossRef]

46. Qiu, G.Y.; Lee, I.B.; Shimizu, H.; Gao, Y.; Ding, G. Principles of sand dune fixation with straw checkerboard technology and its effects on the environment. J. Arid Environ. 2004, 56, 449-464. [CrossRef]

47. Zhang, J.; Zhang, C.; Zhou, N.; Ma, X. Spatial pattern of grain-size distribution in surface sediments as a result of variations in the aeolian environment in China's Shapotou railway protective system. Aeolian Res. 2011, 3, 295-302. [CrossRef]

48. Feng, X.; Li, S.Y.; Xu, X.W. Wind tunnel test on effectiveness of vinyl acetate sand-fixing agents on sand fixation. J. Soil Water Conserv. 2015, 295, 61-65. (In Chinese, abstract in English).

49. Ohkuro, T.; Nemoto, M. Vegetation and soil restoration process by grazing control at desertified sandy grassland in semi-arid regions of Northeast China. J. Jpn. Inst. Landsc. Archit. 1997, 60, 500.

50. Li, S.G.; Harazono, Y.; Zhao, H.L.; He, Z.Y.; Chang, X.L.; Zhao, X.Y.; Zhang, T.H.; Oikawa, T. Micrometeorological changes following establishment of artificially established artemisia vegetation on desertified sandy land in the Horqin sandy land, China and their implication on regional environmental change. J. Arid Environ. 2002, 52, 101-119. [CrossRef]

51. Lancaster, N.; Baas, A. Influence of vegetation cover on sand transport by wind: Field studies at Owens Lake, California. J. Br. Geomorphol. Group 1998, 23, 69-82. [CrossRef] 